\title{
Internal Reflection Sensor for the Cone Penetrometer
}

\author{
Topical Report \\ June 19, 1997
}

\author{
By \\ Job Bello
}

Work Performed Under Contract No.: DE-AR21-96MC33079

For

U.S. Department of Energy

Office of Fossil Energy

Federal Energy Technology Center

P.O. Box 880

Morgantown, West Virginia 26507-0880

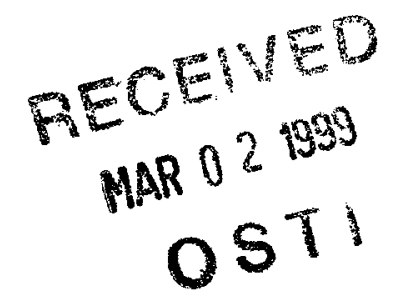

By

EIC Laboratories, Inc.

111 Downey Street

Norwood, Massachusetts 02062 


\section{Disclaimer}

This report was prepared as an account of work sponsored by an agency of the United States Government. Neither the United States Government nor any agency thereof, nor any of their employees, makes any warranty, express or implied, or assumes any legal liability or responsibility for the accuracy, completeness, or usefulness of any information, apparatus, product, or process disclosed, or represents that its use would not infringe privately owed rights. Reference herein to any specific commercial product, process, or service by trade name, trademark, manufacturer, or otherwise does not necessarily constitute or imply its endorsement, recommendation, or favoring by the United States Government or any agency thereof. The views and opinions of authors expressed herein do not necessarily state or reflect those of the United States Government or any agency thereof. 


\section{DISCLAIMER}

Portions of this document may be illegible in electronic image products. Images are produced from the best available original document. 


\begin{abstract}
The objectives of this project are to design, assemble, test, and demonstrate a prototype Internal Reflection Sensor (IRS) for the cone penetrometer. The sensor will ultimately be deployed during site characterization with the goal of providing real-time, in situ detection of NonAqueous Phase Liquids (NAPLs) in the subsurface. In the first phase of this program, we have designed and assembled an IRS module that interfaces directly to a standard cone penetrometer system. Laboratory tests demonstrated that the sensor responds in real-time to a wide variety of "free phase" NAPLs without interference from natural materials such as water and soil of various types or dissolved contaminants. In a preliminary field test, the sensor was able to locate NAPLs at thin, discrete depths in a soil test pit when deployed with a cone penetrometer. Ruggedness of the device was tested with a series of penetrometer pushes to the depth of refusal at a clean location. There was no visible damage to the sensor and its performance did not change in the course of these experiments. Based on the successes of the Phase I program, it is recommended that the project proceed to full-scale demonstration in Phase II.
\end{abstract}


ABSTRACT

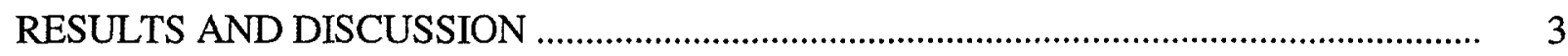

Task 1. Prototype Design and Fabrication...................................................................... 3

Task 2. Prototype Testing ....................................................................................... 4

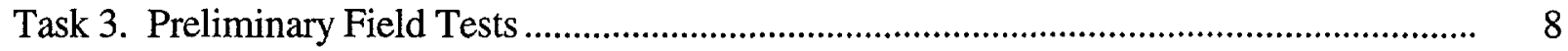

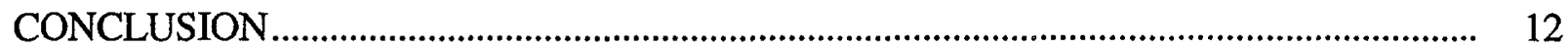




\section{INTRODUCTION}

The presence of NonAqueous Phase Liquids (NAPLs) at U.S. Department of Energy (DOE) sites is cause for concern because these materials pose a long-term threat to drinking water supplies. By definition, NAPLs are free phase chemicals with low water solubilities, existing in soil and groundwater as undiluted "pools." These chemical pools are major contamination sources that are depleted only very slowly by dissolution into large volumes of water. The result is widespread pollution that can continue for many years if the NAPLs are not located and removed. Locating NAPLs is a challenging task, complicated by the fact that subsurface NAPLs are not stationary. Instead, larger pools can break up into much smaller ones that migrate (mostly through cracks and fissures) to other locations.

NAPLs fall into two categories based on their densities: Dense NAPLs (DNAPLs) are denser than water and sink in an aquifer, Light NAPLs (LNAPLs) are less dense than water and float. The most common DNAPLs are chlorinated hydrocarbon solvents such as trichloroethylene (TCE), tetrachloroethylene (perchloroethylene, PCE), carbon tetrachloride, and chloroform which have been found in many locations such as Savannah River (TCE, PCE), Hanford (carbon tetrachloride), LLNL (TCE), and ORNL (1,1,1-trichloroethane). The most common LNAPLs are fuels such as gasoline, diesel, and heating oils. Fuel contamination is a major problem at numerous DOE sites, most notably LLNL (gasoline), INEL (20,000 gallons of Texas Regal Oil), and Savannah River (diesel fuel).

Because of the significant threat posed by NAPLs, it is important that they be located during site characterization and quickly immobilized or removed. Remote, non-intrusive techniques that "look" into the subsurface for NAPLs would be ideal for this application because intrusion can open up new pathways for NAPL migration. Unfortunately, the non-intrusive approach is technically

unfeasible. Instead, devices such as the cone penetrometer, geoprobe, or hydropunch have been developed to probe the subsurface with minimal intrusion. These devices simply push soil aside during deployment, producing a hole about 2 inches in diameter, which can be filled with grout after measurements are performed. This approach disturbs the soil far less than conventional rotary drill boring and produces no waste. Cone penetrometers have received particular attention due to their deeper profiling capabilities. A variety of sensors, most of them geophysical, have been developed for the cone penetrometer but none of them meets DOE's need for NAPL detection. Geophysical techniques such as resistivity and conductivity have been investigated most for NAPL detection, but have been shown to be ambiguous when trying to locate NAPLs. In particular, many natural soil types produce a false indication of contamination. Another limitation of these methods is the need for an uncontaminated soil reference. Usually this means that data must be collected from other onsite locations assumed to be clean and extrapolated to the actual penetration location a time-consuming and inexact procedure at best.

DOE clearly has a need for a reliable (better) NAPL sensor that can be deployed in a cone penetrometer or similar subsurface delivery system for safer, in situ characterization. The primary requirements of the sensor are that it detect NAPLs in real time (faster) without responding to water, soil, or other natural subsurface constituents. Real-time response capability is essential 
because data is collected "on-the-fly" at cone delivery speeds of $2 \mathrm{~cm} / \mathrm{sec}$ or faster. Sensors that respond slowly or require long measurement times to achieve adequate sensitivity could easily miss a thin NAPL plume. A related issue is spatial resolution - the sensor must also be able to locate NAPLs on the centimeter scale, or less. The ability to distinguish between "free phase" NAPL and dissolved contaminants is also important because regulations governing the two are different. Additional requirements are that the sensor be of compact size and low cost, meeting DOE objectives for more fieldworthy, cheaper characterization.

The objective of this project is to design, construct and deploy an Internal Reflection Sensor (IRS) for the cone penetrometer that locates DNAPLs and LNAPLs of interest to DOE in real time. The IRS will meet the performance requirements outlined above in a relatively inexpensive device small enough to be fully housed in a standard penetrometer cone.

The project is divided into two phases, reaching the preliminary field testing stage in less than 1 year, during the first phase of the project. The second, 6-month phase of the program will be devoted to field demonstration of the technique at a NAPL contaminated DOE site and delivery of a working sensor to DOE personnel.

Specific goals of the Phase I program are to:

1. Design and fabricate a prototype IRS for the cone penetrometer.

2. Test the IRS in the laboratory and in a cone penetrometer under controlled field conditions. 


\section{RESULTS AND DISCUSSION}

\section{Task 1. Prototype Design and Fabrication}

An IRS system compatible with a cone penetrometer has been designed and fabricated. A schematic of the down-hole sensor module is shown in Figure 1 and appended engineering drawings. The outer housing of the module is constructed of hardened steel, and all internal pieces are manufactured of stainless steel. Key sensing elements include a microlaser source, sapphire prism, and photodiode detector. The microlaser is a low power device $(<120 \mathrm{~mA} @ 5 \mathrm{~V}$, battery compatible) and the photodiode requires no power for operation. The microlaser beam establishes the sensing area at $10 \mathrm{~mm}^{2}$, which provides for high spatial resolution when the sensor performs measurements in the subsurface. Only four electrical conductors (two for laser power and two for detector signal) are needed for the device. Each optical element is preassembled into a mount that can then be securely inserted, yet be easily removed from the housing if replacement is necessary. The removable mount also contains a 0.25 inch diameter channel through which a standard cone penetrometer cable can pass (not shown in the figure, see discussion below).

Once the mounted optical elements are assembled and aligned in the housing, all components are fixed rigidly in place with a combination of locking screws and epoxy. There is no requirement for moving parts in the system, which renders it an extremely rugged and stable device. End caps, one of which is equipped with a strain relief assembly for the electrical cable, provide protection from dirt, water, etc. A hollow tube connects the two end caps and runs through the removable laser/detector unit, providing a pass-through channel for the cone penetrometer electrical cable. The overall diameter of the 13-inch long down-hole sensor module is 1.75 in, a standard cone penetrometer rod diameter. For preliminary field testing, both ends of the housing were threaded for compatibility with Applied Research Associates' cone penetrometer rods.

Internal Body Slides into the Housing and
Holds the Laser (L) and Detector (D)

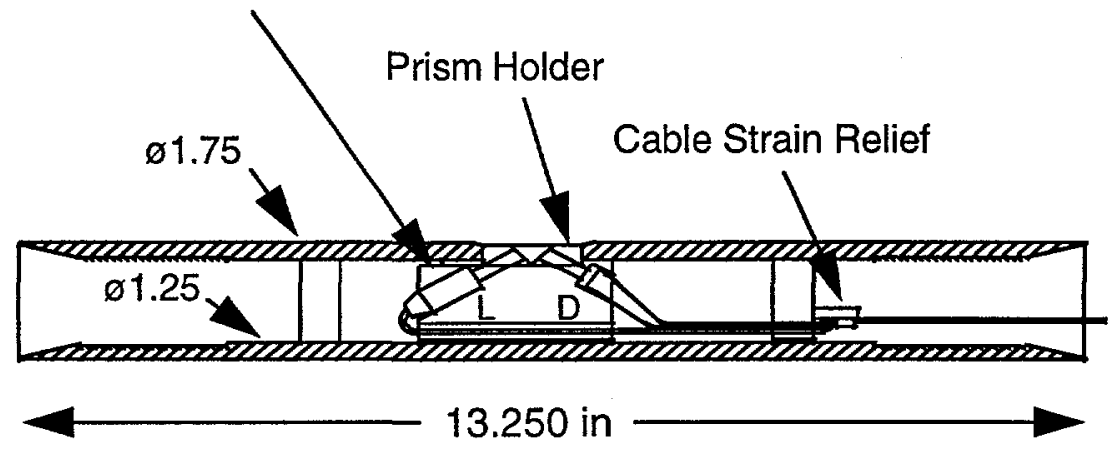

Figure 1. Schematic representation of the down-hole IRS module.

For stand-alone laboratory testing, the sensor module was interfaced to a portable computer data acquisition system. Although the IRS signals are large enough that electrical noise should not 
become a problem even at the greatest measurement depths (150-200 ft), we decided to employ a new down-hole, 8-channel analog-to-digital (A/D) system developed for DOE by UTD, Incorporated (Newington, VA) for data acquisition. The UTD system is uniquely configured to fit inside a cone penetrometer rod and performs both signal amplification and A/D conversion downhole. This approach has the advantage of minimizing noise and loss of signal in deep pushes. The A/D system was connected through a small (6in $x$ 6in $x$ 2in), up-hole power box to the serial port of a laptop computer. The software available from UTD was rudimentary; therefore, we wrote our own routines for data acquisition, display, and storage. The A/D system worked well in all subsequent experiments and was used to collect the data in Task 2.

\section{Task 2. Prototype Testing}

The prototype, stand-alone IRS system was tested in our laboratory to validate its performance for NAPL characterization. To evaluate any potential interference from naturally occurring materials, a series of soil and water samples was tested first. Water samples ranged from clean distilled water to murky stream and pond waters. Soils included organic rich topsoil, sand, and several uncontaminated clays obtained from the Savannah River Site (SRS), where it is proposed to conduct the field evaluation as discussed later in this report. The clays were collected from depths where NAPL contamination has been found and therefore represent a likely background matrix for NAPL detection at SRS. The soils were tested both wet (saturated with water) and dry.

The tests were performed by placing each material firmly in contact with the sensing prism face. Any response was measured as a decrease in laser light internally reflected by the prism; hence, a decrease in the voltage measured from the photodiode detector. Table 1 summarizes the results of the background tests, which clearly validate that the system does not respond to naturally occurring materials found in the subsurface under the test conditions. For the soils, response was unaffected by moisture content - only the dry soil results are included in the table. Neither dense clays nor loose, gravelly materials posed an interference to the sensor. Because the prism is made of sapphire, none of the materials scratched or damaged the face.

- Next, the response of the system was characterized with a series of 23 "pure" test samples selected to cover a wide range of refractive indices $\left(n_{D}\right)$. Many of the samples were chosen in part due to their lower volatility, which ensured that they remained as a thin layer on the sensing surface while the measurement was being made. Figure 2 is a plot of percent reflectivity vs. refractive index for the test compounds included in Table 2. As expected, the internal reflectance decreases with increasing refractive index. All of the compounds, with the exception of acetone, gave strong, easily measured responses. Although the instrument can be configured to respond strongly to acetone, some natural waters have a comparable refractive index (1.36) and would produce a false positive response. We have chosen to configure the device conservatively, so that only materials of refractive index about 1.38 and higher produce strong responses. However, this refractive index cutoff is sufficiently low such that virtually all the common NAPLs will produce a response. The most likely NAPLs to be encountered at DOE sites are chlorinated solvents and hydrocarbon fuels, which have relatively high refractive indexes as listed in Tables 2 and 3, and will produce strong responses. 
Table 1. Water and Soil Background Test Results.

\begin{tabular}{|c|c|c|c|c|}
\hline Sample & Starting mV & Final mV & $\Delta \mathrm{mV}$ & \% Reflectivity \\
\hline Distilled Water & 203 & 202 & 1 & 99.5 \\
\hline Tap Water & 204 & 204 & 0 & 100 \\
\hline Stream Water & 204 & 204 & 0 & 100 \\
\hline Pond Water & 206 & 205 & 1 & 99.5 \\
\hline Topsoil Outside EIC & 206 & 204 & 2 & 99.0 \\
\hline Saudi Arabian Sand & 204 & 204 & 0 & 100 \\
\hline SRS Gray/Brown Clay & 205 & 204 & 1 & 99.5 \\
\hline SRS Red Clay & 205 & 204 & 1 & 99.5 \\
\hline
\end{tabular}

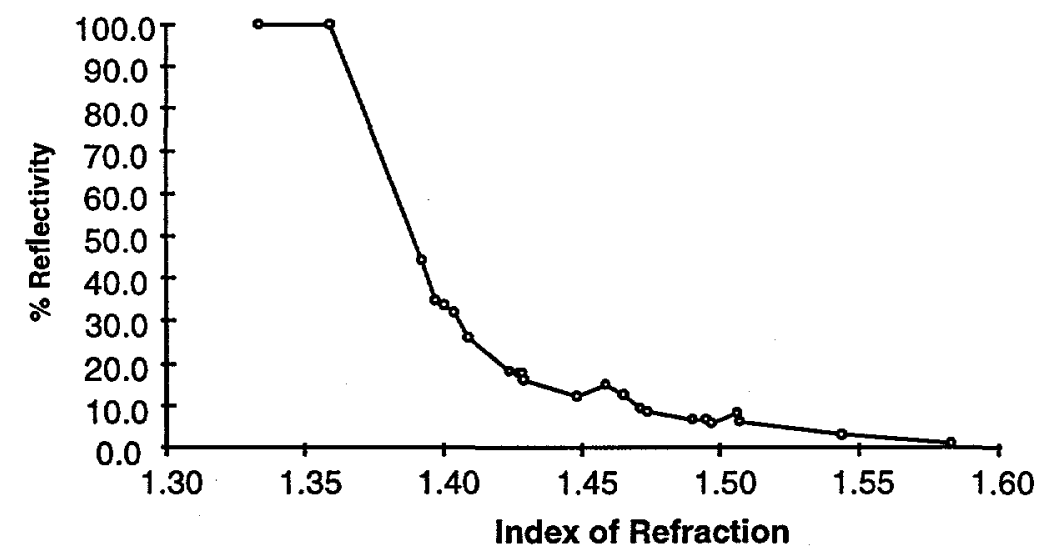

Figure 2. IRS response to various NAPLs before preliminary field testing.

In a third series of experiments, NAPLs were spiked into soil and water and the responses of the mixtures were measured with the IRS system. The water samples were prepared by adding an excess of each NAPL to tap water in a closed vial to produce the maximum aqueous concentration possible. The vial was shaken and allowed to equilibrate for several hours (to ensure saturation of the water layer) before a sample was pipetted from the water layer and placed on the IRS sensing face for measurement. Soil samples were prepared by adding $1 \mathrm{~mL}$ of NAPL to $2 \mathrm{~g}$ of a topsoil collected from outside our research facility, either dry or wet, in a vial and mixing with a spatula. In some cases, it was difficult to prepare a homogeneous sample with the wet soils due to the immiscibility of the NAPLs with water. 
Table 2. "Pure" NAPL Test Results.

\begin{tabular}{|c|c|c|c|c|c|}
\hline NAPL & $\mathrm{n}_{\mathrm{D}}$ & Starting $\mathrm{mV}$ & Final $\mathrm{mV}$ & $\Delta \mathrm{mV}$ & \% Reflectivity \\
\hline Tap Water & 1.333 & 311 & 311 & 0 & 100 \\
\hline Acetone & 1.359 & 311 & 311 & 0 & 100 \\
\hline Isooctane & 1.392 & 310 & 138 & 172 & 44.5 \\
\hline 1-Butanol & 1.397 & 310 & 108 & 202 & 34.8 \\
\hline Amyl Acetate & 1.400 & 310 & 105 & 205 & 33.9 \\
\hline 3-Methyl-1-Butanol & 1.404 & 310 & 100 & 210 & 32.3 \\
\hline Decane & 1.409 & 310 & 81 & 229 & 26.1 \\
\hline Cyclohexane & 1.424 & 311 & 57 & 254 & 18.3 \\
\hline N,N-Dimethylformamide & 1.427 & 311 & 55 & 256 & 17.7 \\
\hline Dimethyl Adipate & 1.428 & 310 & 55 & 255 & 17.7 \\
\hline Ethylene Glycol & 1.429 & 309 & 50 & 259 & 16.2 \\
\hline Cyclohexanone & 1.448 & 311 & 38 & 273 & 12.2 \\
\hline Carbon Tetrachloride & 1.459 & 310 & 47 & 263 & 15.2 \\
\hline$\alpha$-Pinene & 1.465 & 310 & 39 & 271 & 12.6 \\
\hline Limonene & 1.471 & 309 & 29 & 280 & 9.4 \\
\hline Glycerol & 1.474 & 311 & 27 & 284 & 8.7 \\
\hline Dibutylphthalate & 1.490 & 310 & 21 & 289 & 6.8 \\
\hline ASE30 Motor Oil & 1.495 & 310 & 21 & 289 & 6.8 \\
\hline Toluene & 1.497 & 310 & 19 & 291 & 6.1 \\
\hline Tetrachloroethylene & 1.506 & 310 & 26 & 284 & 8.4 \\
\hline Pyridine & 1.507 & 310 & 20 & 290 & 6.5 \\
\hline Benzaldehyde & 1.544 & 310 & 10 & 300 & 3.2 \\
\hline Aniline & 1.583 & 309 & 4 & 305 & 1.3 \\
\hline
\end{tabular}

The results for the saturated water samples are presented in Table 3. Clearly, the NAPLs do not produce an appreciable IRS response when dissolved at maximum concentration in water. This is not surprising as the solubilities of the NAPLs are less than $1 \%$ in water and therefore change the refractive index of water by less than 0.01 units. The IRS has been configured so that a refractive index shift of this magnitude from water goes undetected. This provides the necessary discrimination between "free phase" NAPLs and dissolved contaminants. 
Table 3. Test Results for NAPLs Dissolved at Maximum Concentration in Water.

\begin{tabular}{|c|c|c|c|c|c|}
\hline NAPL & $\mathrm{n}_{\mathrm{D}}$ & Starting $\mathrm{mV}$ & Final mV & $\Delta \mathrm{mV}$ & \% Reflectivity \\
\hline Trichloroethylene & 1.476 & 210 & 209 & 1 & 99.5 \\
\hline Tetrachloroethylene & 1.506 & 210 & 209 & 1 & 99.5 \\
\hline Toluene & 1.497 & 211 & 211 & 0 & 100 \\
\hline Gasoline & ---- & 210 & 209 & 1 & 99.5 \\
\hline 10W-40 Motor Oil & 1.495 & 209 & 206 & 3 & 98.5 \\
\hline
\end{tabular}

The spiked soil sample results are summarized in Table 4. The overriding trend in the data is that the response increased (\% reflectivity decreased) as the refractive index of the test compound increased. This is the same trend as for the "pure" NAPLs and confirms that the sensor was responding only to the NAPL. The wet and dry soil results were comparable; the wet soil gave a slightly lower response in nearly all cases. This is presumably due to part of the sensing region being occupied by water, rather than NAPL. The largest difference was for 1-butanol. We found it especially difficult to determine if the butanol was mixed uniformly with the wet soil. The variance is accentuated by the fact that 1-butanol falls on the steep portion of the \% reflectivity vs. refractive index curve (see Figure 2). Trichloroethylene, one of the most prevalent NAPLs at DOE facilities, gave a strong response in soil.

Table 4. Test Results for NAPLs Mixed With Dry and Wet Soils.

\begin{tabular}{|c|c|c|c|c|c|}
\hline Sample & $\mathrm{n}_{\mathrm{D}}$ & Starting $\mathrm{mV}$ & Final mV & $\Delta \mathrm{mV}$ & $\%$ Reflectivity \\
\hline Acetone in Dry Soil & 1.359 & 204 & 201 & 3 & 98.5 \\
\hline Acetone in Wet Soil & 1.359 & 204 & 200 & 4 & 98.0 \\
\hline 1-Butanol in Dry Soil & 1.397 & 203 & 68 & 135 & 33.5 \\
\hline 1-Butanol in Wet Soil & 1.397 & 203 & 110 & 93 & 54.2 \\
\hline Gasoline in Dry Soil & --- & 204 & 29 & 175 & 14.2 \\
\hline Gasoline in Wet Soil & ---- & 204 & 40 & 166 & 19.4 \\
\hline Trichloroethylene in Dry Soil & 1.476 & 205 & 18 & 187 & 8.8 \\
\hline Trichloroethylene in Wet Soil & 1.476 & 206 & 20 & 186 & 9.7 \\
\hline ASE30 Motor Oil in Dry Soil & 1.495 & 203 & 9 & 194 & 4.4 \\
\hline ASE30 Motor Oil in Wet Soil & 1.495 & 207 & 14 & 193 & 6.8 \\
\hline Aniline in Dry Soil & 1.583 & 203 & 1 & 202 & 0.5 \\
\hline Aniline in Wet Soil & 1.583 & 204 & 2 & 202 & 1.0 \\
\hline
\end{tabular}




\section{Task 3. Preliminary Field Tests}

Field testing of the IRS was conducted the week of June 8, 1997 in collaboration with Applied Research Associates at their New England Division Headquarters in South Royalton, Vermont. The two major objectives of the preliminary tests were to: (1) test IRS durability during a real penetration and (2) evaluate the system's ability to detect and locate NAPLs in a controlled test pit. Detection entails responding to NAPLs contacting the face of the internal reflection element. A measured response indicates only the presence of NAPL and does not identify the contaminant. Location of NAPLs refers to establishing the vertical extent of contamination by following sensor response as a function of depth. As with all optical techniques deployed in a cone penetrometer, there is no provision for providing measurements at any appreciable lateral distance from the cone.

The test pit experiments were conducted first using ARA's cone penetrometer "skid" rig. The skid consisted of a cone penetrometer mounted on a trailer with lead weights added for ballast. A portable data system was set up in the back of a pickup truck parked nearby and was connected to the rig through an electrical cable. In order to maximize the depth of each push for the IRS within the constraints of a 55-gallon drum (about $3 \mathrm{ft}$ deep), a short uninstrumented cone tip was configured ahead of the IRS for these tests. This resulted in the sensing element being 12 inches behind the cone tip. The four-conductor IRS cable was connected to the cone penetrometer data system cable, which had been pre-strung through the penetrometer rods. The data system supplied $+4 \mathrm{dcV}$ to power the laser and $10 \mathrm{X}$ amplification of the detector signal. It also provided real-time readout and display of both depth and IRS response during each push.

The test pit consisted of a cemented hole in the ground slightly larger than the 55-gallon drum "sample." A forklift was used to place the drum in the pit and position the skid over the drum. Figure 3 shows the test sample prepared by Applied Research Associates. First, clean sand was placed in the drum to a depth of about 15 in. Then a black plastic bag containing some of the same sand wetted with weathered motor oil was placed in the drum. The oil sample was about 3-4 in thick and covered most of the cross-sectional area of the drum. Approximately 5 in of clean sand was then used to cover the sample. A second, smaller and thinner (about 1 in thick) sample of tetrachloroethylene (perchloroethylene) saturated sand in a plastic bag was placed in the center of the drum and covered with 1-2 in of a different, local sandy loam soil. A final sample of gasoline in the sandy loam (not contained in a plastic bag) was placed in the drum as a small, 1 in thick patch centered in the drum (see Figure 3 ). The remainder of the drum was filled with moist sandy loam.

Three pushes were made into the drum. The first, slightly off-center push hooked the edge of the tetrachloroethylene bag and dragged a portion of the sample down the hole. This smeared the contamination and produced a real, but invalid response over a depth of about a foot. The other two pushes went "cleanly" through the samples, providing accurate profiles of the contamination. The results are presented in Figure 4. 


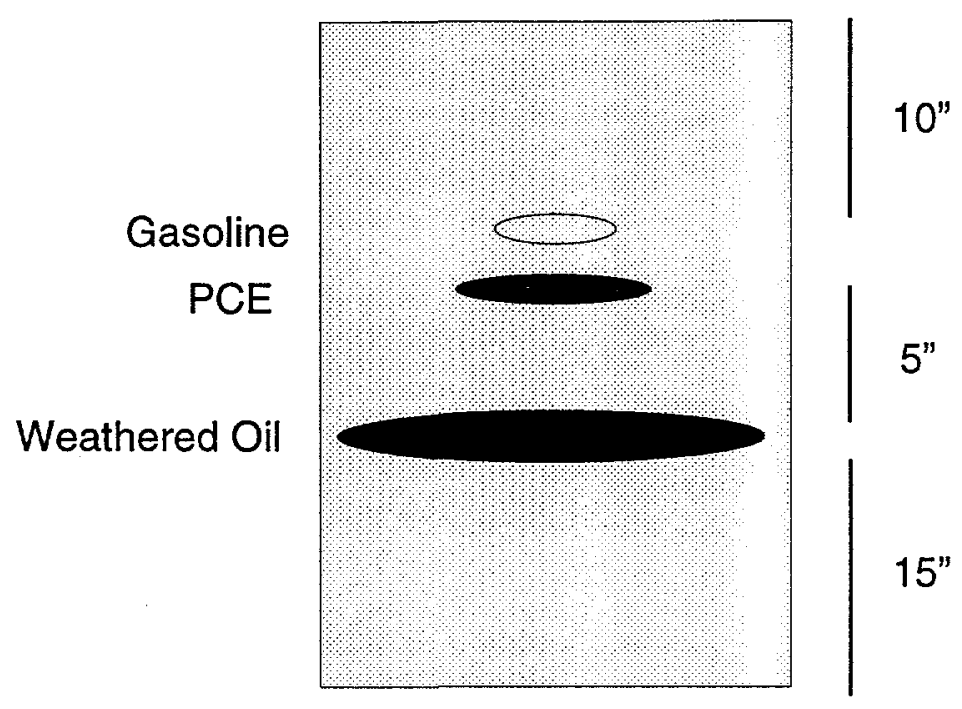

Figure 3. Cross-sectional view of NAPL test samples prepared in a 55-gallon drum.

The first of the two valid pushes (Push \#2) was directed toward one edge of the drum. Therefore, it missed the two top contaminant layers, encountering just the lower weathered oil layer. The trace in Figure 4 indicates a strong IRS response to the weathered oil, beginning immediately at the depth at which the top of the material was buried (about 18 in $=32$ in measured - 12 in tip-to-sensor distance - 2 in "offset" at top of hole). Note that the response persists about twice as long as expected based on the thickness of the sample placed in the drum. We attribute this to the loose packing of the freshly prepared soil sample. Loose packing may have allowed some of the contaminated sand to migrate with the cone tip and also provided less effective cleaning of the sensing surface than the more tightly packed soils of the real subsurface. Considering that motor oil is viscous and difficult to clean from glass surfaces, the results are excellent. Note also that the IRS gave no response to soils of different types or water contents, confirming again that the sensor does not respond falsely to natural subsurface constituents.

The second of the two valid pushes (Push \#3) was positioned very close to the center of the drum. Therefore, the sensor encountered all three contaminants. Even at a much faster push rate (note the lower point density compared to the previous trace) approaching that normally used in the field, all three contaminants were easily detected. The gasoline and tetrachloroethylene layers were fully resolved from one another with only an inch or two of soil separating them. Although the layers of these contaminants were thinner, it is still evident that the response to those materials did not persist to the same extent as for the oil. This can be attributed to the lower viscosity of these compounds, allowing them to be more easily cleaned from the sensing surface during a push. It is also notable that the profile for the oil layer was the same as that observed in the previous push, demonstrating the reproducibility and reliability of the technique for locating NAPLs. 
Push 2

IRS (deV)

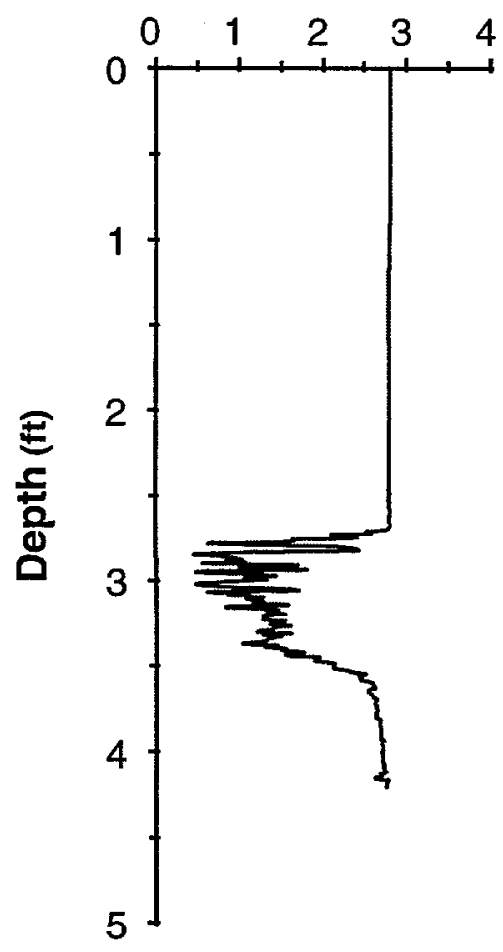

Push 3

IRS (dcV)

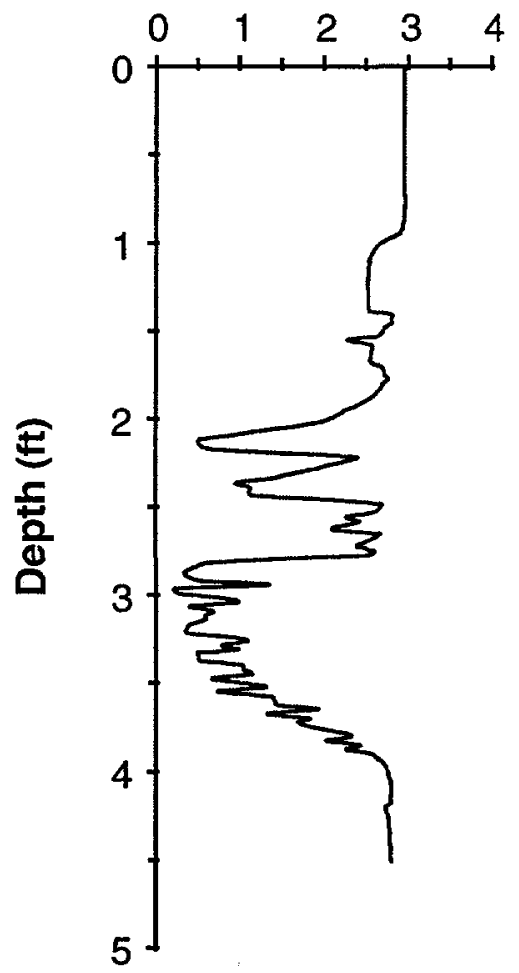

Figure 4. Cone penetrometer IRS results for the NAPL test pit sample.

As a test of sensor ruggedness, four pushes were conducted at a farm site near the Applied Research Associates facility. The penetrometer skid rig was towed to the site with a tractor and setup as for the test pit experiments. However, the cone tip was replaced with a fully instrumented cone for these tests. The longer, instrumented cone placed the IRS sensing element 33 inches from the tip. Standard cone parameters and IRS response were monitored in real-time during the pushes. The first push reached refusal at only $19 \mathrm{ft}$; however, we were able to eclipse thirty feet in each of the other three pushes for a total deployment of over $100 \mathrm{ft}$.

The results of the four pushes are presented in Figure 5. As expected, no IRS responses were measured at this clean site. The down-hole module performed well throughout the tests, with no equipment failure even at points of high resistance and "hard" refusal. At these positions, some minor baseline shifts were observed. These may be due in part to temperature changes as frictional forces vary. We have measured the temperature coefficient of the sensor to be approximately $1 \mathrm{mV} / \mathrm{C}$ in the range $20-40^{\circ} \mathrm{C}$. This temperature effect is clearly shown in Figure 5 for the first push, where the sensor baseline drifted upward as it went from the hot sun (where is had been for almost an hour) into the cool ground. Unfortunately, the cone penetrometer was not equipped with a temperature sensor to confirm this hypothesis. It is important to note, however, that the 
magnitude of these effects is small when compared to the magnitude of the sensor response to NAPLs.

Upon completion of the preliminary field tests, we repeated the laboratory tests with the 23 NAPLs of varying refractive index. The results shown in Figure 6 are the same as those obtained prior to the field tests (see Figure 2). This demonstrated that there was no degradation in performance of the sensor as a result of the field testing. There was also no physical damage to the sensor that we could observe. The sensing prism face was unblemished.

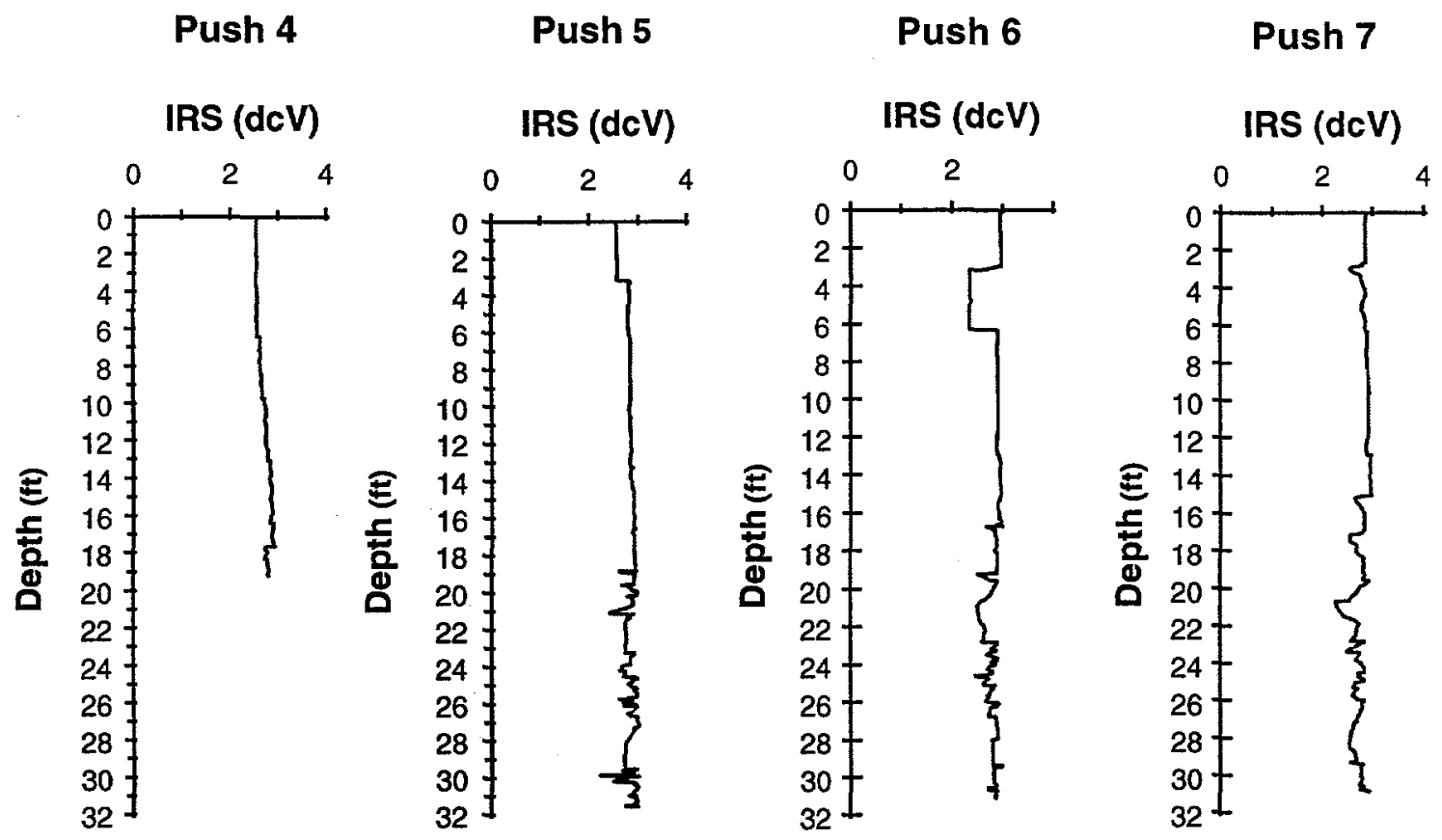

Figure 5. IRS response during cone penetrometer deployment.

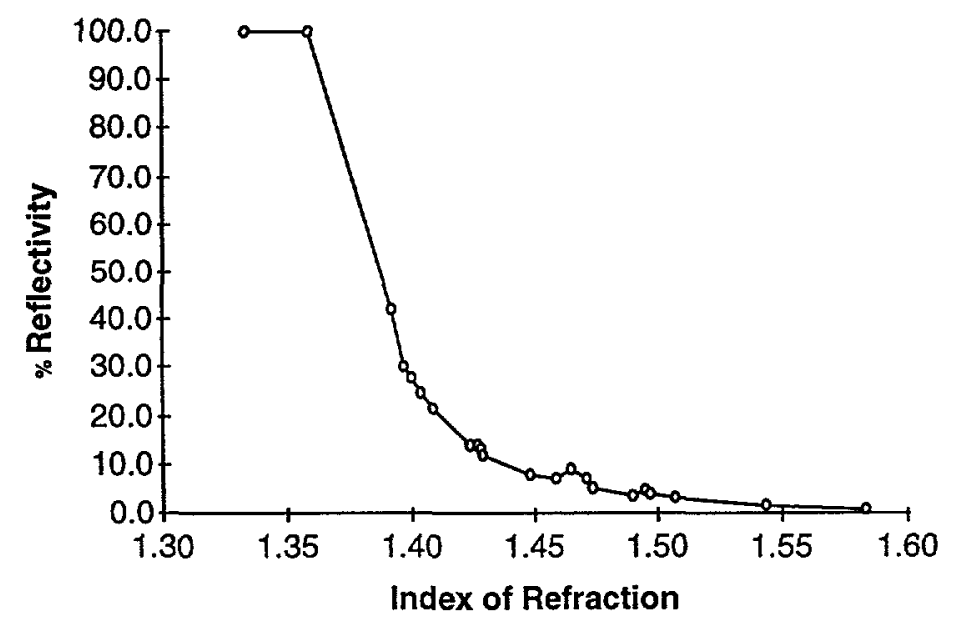

Figure 6. IRS response to NAPLs after preliminary field testing. 


\section{CONCLUSION}

Each of the Phase I program objectives has been successfully met. We have assembled and tested a prototype IRS instrument compatible with operation in a standard cone penetrometer. The device performs measurements with high spatial resolution $\left(10 \mathrm{~mm}^{2}\right)$ in real-time. Extensive laboratory testing has shown that the sensor responds strongly to a wide range of NAPLs of concern to DOE without interference from natural subsurface materials comprising soil and groundwater. The device also differentiates "free phase" NAPLs from dissolved contaminants, even when the contaminants are present at their maximum solubility limit.

In a blind field test we were able to locate NAPLs at discrete depths in real-time during a cone penetrometer push into a soil test pit. The sensor was also integrated into a fully instrumented cone penetrometer and multiple pushes were performed to the depth of refusal. The sensor withstood this preliminary deployment well, demonstrating no change in performance from before the test.

Based on the successful results of the Phase I base program, we recommend that the optional Field Testing (Task 4, Phase II) phase of this program proceed as planned. It is recommended that the field testing take place at SRS where NAPLs are known to be present and a cone penetrometer truck is stationed for this type of testing. Prior to the final field test at SRS, we will be redesigning the probe to make it more fieldworthy (waterproof, etc.) Site contacts there (Mr. Joe Rossabi, Ms. Carol Eddy-Dilek) are interested in testing the technology. A preliminary Field Operations Plan for testing at SRS has been submitted separately from this report. 